\title{
Afeto, imagem e memória no filme Como esquecer: estudos contemporâneos $^{1}$
}

\author{
Affection, image and memory in the film So Hard to Forget: contemporary studies \\ Afecto, imagen y memoria en la película Como olvidar: estudios contemporáneos
}

DOI: $10.1590 / 1809-5844201828$

\section{Wilton Garcia ${ }^{1}$}

http://orcid.org/0000-0001-9598-2323

${ }^{1}$ (Universidade de Sorocaba, Pró-Reitoria de Pós-Graduação, Pesquisa, Extensão e Inovação, Programa de Pós-Graduação em Comunicação e Cultura. Sorocaba - SP, Brasil)

\section{Resumo}

A memória vivenciada em determinados filmes exibe, estrategicamente, predicações de afeto como pressuposto para pesquisar fragmentos do filme brasileiro Como esquecer (2010), de Malu De Martino. Aqui, o discurso fílmico expõe a intimidade e instiga a descrição da diversidade cultural/ sexual. Afeto, imagem e memória são categorias elencadas ao longo do texto. Assim, esta pesquisa foi realizada por meio de fontes primárias e secundárias, ao considerar a leitura fílmica com os chamados estudos contemporâneos em uma abordagem teórico-metodológica. Os resultados apontam para vestígios sobre corpo, gênero e performance na discussão da diversidade no cinema nacional contemporâneo.

Palavras-chave: Afeto. Imagem. Memória. Cinema Brasileiro. Estudos Contemporâneos.

\begin{abstract}
The experienced memory in certain movies displays strategically affection predications as a prerequisite to research Brazilian film fragments So Hard to Forget (2010), by Malu De Martino. Here, the film discourse exposes the intimacy and instigates the description of the cultural/sexual diversity. Affection, image and memory are the categories listed in the text. Thus, this research was carried out through primary and secondary sources, considering filmic reading with so-called contemporary studies on a theoretical and methodological approach. The results point to traces of body, gender and performance in the diversity discussion in contemporary Brazilian cinema.
\end{abstract}

Keywords: Affection. Image. Memory. Brazilian Cinema. Contemporary Studies.

\section{Resumen}

La memoria experimentado en cierta película muestra estratégicamente predicciones afecto como presupuesto a la investigación fragmentos de película brasileñas Como olvidar (2010), Malu De

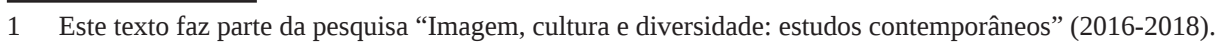


Martino. Aquí, el discurso fílmico expone la intimidad e instiga a la descripción de la diversidad cultural/sexual. El afecto, la imagen y la memoria son las categorías que figuran en el texto. Por lo tanto, esta investigación fue realizada por medio de fuentes primarias y secundarias, teniendo en cuenta la lectura fílmica con los llamados estudios contemporáneos sobre un enfoque teórico y metodológico. Los resultados muestran rastros de cuerpo, el género y el performance en la discusión diversidad en el cine brasileño contemporáneo.

Palabras clave: Afecto. Imagen. Memoria. Cine brasileño. Los estudios contemporáneos.

A intermediação entre exaltar e/ou condenar a diversidade tem a ver com a liberdade de expressão do sujeito, sobretudo no contemporâneo. Na lógica midiática atualmente, ser afetado por outro/a faz parte do discurso cinematográfico como possibilidade de produção de subjetividade, tanto na ficção quanto na realidade. Cada vez mais, as relações humanas representadas no cinema refletem, de modo significativo, a sociedade atual. O cinema contribui para se pensar "novos/outros” parâmetros da diversidade.

O filme Como esquecer (2010), de Malu De Martino, apresenta uma adaptação do romance literário, autobiográfico, de Myriam Campello (2003). A história de Júlia interpretada pela atriz Ana Paula Arósio - pontua ações cotidianas, em um efervescente desfecho entre ficção e realidade, da literatura ao cinema (e vice-versa). Do uso de códigos (verbal, não verbal e/ou sincrético), há um esforço notável na tradução da literatura ao filme (STAM, 2003), no enlace de escrita e audiovisual. Por assim dizer, os diálogos valorizam a palavra em consonância com a imagem, pois cada participante tem uma história para contar.

Aqui, o discurso fílmico expõe a intimidade e instiga a descrição da diversidade cultural/sexual. Eminentemente, um drama de amor lésbico (ALLEN, 1996; WITTIG, 1992) aponta para um final de relação amorosa. Com ênfase na discussão sobre identidade sexual e de gênero, a artimanha fecunda do feminino prevalece no protagonismo de Júlia, que tenta reerguer sua vida diante da perda da amada, Antônia. A sinopse indica:

Júlia é uma professora de literatura inglesa, 35 anos, que luta para reconstruir sua vida depois de viver uma intensa e duradoura relação amorosa com a enigmática Antônia. Em meio a uma série de conflitos internos e diante da necessária readaptação para uma nova vida, não disfarça sua dor enquanto narra suas emoções. Ao longo do filme, ela encontra e se relaciona com outras pessoas que também estão vivendo, cada uma a seu modo, a experiência de ter perdido algo importante em suas vidas. Revela-se uma trama instigante que fala de pessoas comuns enfrentando desafios de superar as dores do passado e a busca por uma nova chance de encontrar a felicidade. (COMO ESQUECER, 2010).

Desse contexto, as formas de composição da informação atuais emergem, estrategicamente, em uma situação híbrida e complexa para refletir acerca dos procedimentos de (re)elaboração do enunciado, em especial na interdisciplinaridade 
de arte, cinema e diversidade. A narrativa fragmentada organiza um território de possibilidades complementares, em que a escritura (inter/trans)textual se faz pelas arestas da intersubjetividade. O campo contemporâneo da comunicação e da cultura, na atualidade, entrecruza questões conceituais, metodológicas, teóricas e políticas (SODRÉ, 2014).

Do ponto de vista midiático, a lente da câmera e o gravador de som (re)velam anotações peculiares. Assim, afeto, imagem e memória são categorias elencadas ao longo do texto. Sendo que tais categorias contribuem para a presença do sujeito na cena contemporânea (GUMBRECHT, 2010). Com isso, os estudos contemporâneos, estrategicamente, convocam uma abordagem teórico-metodológica, a fim de (re)considerar a atualização e a inovação (GARCIA, 2012).

Atualmente, o eixo teórico-político que abrange os estudos de cinema, no Brasil, encontra-se em sintonia com os estudos de gênero, os estudos feministas, bem como os estudos culturais. Há poucas discussões sobre a mulher no cinema (MULVEY, 1983; NAGIB, 2012), em especial quando se trata do cinema brasileiro contemporâneo. Tal fato pede atenção especial ao desdobrar uma leitura crítico-conceitual a respeito dessa fita.

A película, assim, abre espaço para o debate crítico-conceitual acerca da performatividade feminina (CARLSON, 2009), especialmente quando se pensa sobre o atual contexto cinematográfico da diversidade cultural/sexual no país. A presença da mulher no cinema brasileiro hoje emerge de forma marcante, tendo em vista algumas maneiras diversas de agenciar/negociar a imagem feminina (FOSTER, 2003; STAM, 2003). O feminino (re)inscreve um modus operandi para acessar a sensibilidade do afeto, em uma composição intuitiva, para além da subalternidade (SPIVAK, 2010). Com razão, o contexto fílmico produz sentimentos universais de renovação feminina: o amadurecer necessário para se ter autonomia, emancipação e independência. Pensar essa dinâmica seria apostar em diretrizes da identidade sexual e de gênero na (re)invenção das narrativas contemporâneas. Os segredos da natureza humana podem ser (re)velados a partir da ficção cinematográfica.

Este filme, portanto, trata de um drama psicológico de uma mulher em busca de seu lugar no mundo, como professora de literatura inglesa, que acaba de perder o chão. Seu dia a dia mostra a tentativa de se retomar como ser humano, mediante as turbulências do amor para refazer a vida. Como afrontamento, surgem na tela questionamentos e inquietações.

Uma vez ressaltadas essas premissas, aponto para a diversidade cultural/sexual estabelecida na leitura desta proposta fílmica. Embora não haja problema direto sobre a orientação sexual dos personagens (gays e lésbicos), a homocultura enfatiza ações afirmativas e visibilidade (GARCIA, 2004), ao iluminar metaforicamente um retrato diário de Júlia, encenado entre a universidade e a cidade de Pedra de Guaratiba, litoral do Rio de Janeiro, como cenário principal dessa obra. 


\section{Do afeto}

O cinema contemporâneo provoca um olhar a respeito da dimensão humana, a acenar para possíveis vínculos afetivos (PEIXOTO, 2007; FOSTER, 2003; STAM, 2003). Seria a (inter)ligação a um alguém, um referente. Relacionamento que pode ser intenso: talvez, a metáfora do chamado porto seguro equacione um envolvimento. Afinal, afeto serve como tônica das circunstâncias cruciais da diversidade cultural/sexual em cena. Entre amizade e amor, seria a ternura em um espaço relacional. A mediação do sujeito tem a ver com a oportunidade de se permitir tocar e/ou ser tocado, como o despertar para uma sensibilidade mais aguçada nas próprias relações humanas de encontro, aproximação, distanciamento, entre outras (PELBART, 2013)

Desprovida de glamour, a problemática do filme Como esquecer está na insuportabilidade da perda do amor como dilema da protagonista, a qual foi afetada drasticamente pela rejeição. Afetar, assim, requer atingir e/ou ser atingido pelo/a outro/a. O que se aproxima de afeição, apego, complacência e/ou estima entre pessoas. Ou ainda, relações humanas a examinar, provar, aportar, abordar, ancorar, apalpar o sujeito, a vida.

No enredo fílmico, Júlia tenta superar uma dor intragável, após o término do relacionamento de mais de dez anos com a ex-companheira. Parece ser um momento delicado e, ao mesmo tempo, pesado, visto que sua expectativa seria ultrapassar essa fase nebulosa. Porém, tal situação lhe trouxe debilidade, com a negação da ex-namorada (Antônia). Ou seja, seguir em frente, parece ser insuportável para a protagonista, que pede para ser amarrada, em casa, em razão do transtorno dessa paixão devastadora.

A protagonista mistura suas decisões abruptas. Entre a doçura e contragolpes de ira, a dor de Júlia evoca um sentir enfático. Ao perder algo precioso, a protagonista vive apenas de lembranças do que já se foi. Marcada por esse sentir, Júlia percorre um cotidiano triste, arrasado e abafado.

No filme, a voz em off dela afirma: “o amor é sempre um pacto contra o tempo”. Tempo que determina a vida. Do passado ao presente, o cronológico (diacrônico e/ou sincrônico) com flashbacks entrecruza o roteiro, cuja trama expõe embates para suplantar esse amor não correspondido - quiçá, agora, platônico. Vestígios de memória. Um vazio da ausência. Verificam-se desterros de desolação e perplexidade nas ações da protagonista. Para Sarlo (2007, p.9), “o retorno do passado nem sempre é um momento libertador”. Portanto, Júlia prende-se, de modo voraz, ao relacionamento interrompido.

Assim, o/a espectador/a testemunha o enlace (a comunhão) de afeto, desejo, erótica, sensualidade, sexo, entre outros argumentos cinemáticos (FOSTER, 2003). Mais que isso, o discurso embriaga-se com esse amor improvável. Nota-se que se trata de um filme centrado nas dificuldades de lidar com a eminente ausência. Sobrevivente desse fracasso, a personagem principal depara-se com atropelos, desapontamentos e/ou contrariedades. Ela 
tenta sobreviver às emoções de compartilhar momentos difíceis. Desafetos. E a narrativa exprime algumas debilidades com seus problemas para perdoar e, novamente, amar.

Disso, o sentir, também, ajuda a constatar a realidade. Trata-se da condição adaptativa da incomensurabilidade dos fatos que emocionam. Um ato de acolhida cria proximidade, intimidade, privacidade e/ou cumplicidade. Afetar o/a outro/a, conforme a realidade tange um “novo/outro" viver, faz parte das relações. Mexer, agir, movimentar ou deixar a coisa acontecer. Ao experimentar a vida, de fato, o afeto refere-se ao molestar, contagiar, contaminar. Assim como a possibilidade de afligir, comover, abalar, influenciar, tanger. Também, instaura-se o aproximar e o sensibilizar. Todavia, essa escritura fílmica sugere, poeticamente, o afeto para além de encontro e/ou despedida. Um breve passeio orgânico absorvido pela narrativa, em sua pluralidade, expande derivações intersubjetivas (PELBART, 2013).

A mensagem direta do filme articula o amor entre iguais. Dessa forma, o roteiro é explícito quanto ao tema abordado: o amor lésbico. Sem isso, Júlia não está preparada para seguir a vida. Consequentemente, vive abalada com a separação. O rompimento de um matrimônio de anos a fio provoca estragos. Por isso se ausenta de qualquer possibilidade de avançar. Eis um desamparo potente, visto que não consegue livrar-se das (de)marcações desse antigo amor. No filme, situações conflitantes tecem um emaranhado de ideias desconexas, que faz emergir suas fragilidades. A narrativa apodera-se da ênfase no sentir pessoal. Ressaltam-se características pontuais, cujos sentimentos prosaicos mostram amor, desejo, tensão, medo, saudade, solidão, paixão, entre outros.

$\mathrm{Na}$ cadência rítmica de imagem/som, deve-se considerar as derivativas de uma política do afeto (GARCIA, 2004), ao despertar estratificações do corpo e da personalidade do/a outro/a, que apostam na tônica da diversidade, da diferença e da alteridade. O que (re) dimensiona grupos e classes sociais (HELLER et al, 2004), em uma intenção extra fílmica (STAM, 2003), a propor uma política do afeto. Isto é, a compreensão de parâmetros da cultura contemporânea (AGAMBEN, 2009; BAITELLO JR, 2012) atualiza a vida.

\section{Da imagem}

Logo no início do filme, percebe-se uma sequência de imagens desconsertadas. Parecem cenas caseiras de vídeo. Do ponto de vista comunicacional, a câmera na mão balança, ao fragmentar imagem e som com ruídos, como intervenções estéticas. Isso determina a precariedade técnica na captação particular de gestos sublimes em uma performance sutil (PELBART, 2015). Talvez fossem flashbacks. E o/a espectador/a saberá apenas mais à frente que se trata de pedaços de lembranças do que se foi. Memórias. Retorno do já acontecido! Ou, ainda, o que se registrou simplesmente em vídeo, fotografia, carta. São pistas de uma relação afetiva conturbada. Cenas que, por vezes, se repetem no écran. 
Da tela escura (fade out), surge a claridade de um céu azul e aberto com nuvens brancas e o sol radiante bem ao centro. A película começa mostrando o sol brilhante que aquece e ilumina o dia das apaixonadas. Na sequência, a câmera desliza, em movimento rápido, sob um muro de flores rosa, a destacar a protagonista. Os créditos com os nomes de atrizes e atores sobrepõem à grande tela do cinema. Júlia passeia, como turista, com a amada Antônia. Vagueiam por jardins, bancos, praças e palácios com arquitetura europeia. Brincam, exploram e apreciam a paisagem. Literalmente, tudo são flores, pois a cena segue com Antônia filmando Júlia em meio aos canteiros coloridos e bem cuidados dos jardins londrinos. O lugar bucólico, com arquitetura extraordinária, parece ser a cidade de Londres, Inglaterra. Pequenas brincadeirinhas entre as amantes permeiam a viagem na capital inglesa.

Posando para a câmera ou em ocasião de distração, contemplando a paisagem, Júlia seria, por suposto, a grande estrela do vídeo. E Antônia, que nunca aparece na cena, insiste em filmar a amada diretamente, em movimento e/ou parada. De fato, os registros audiovisuais invadem paulatinamente a privacidade do casal (Júlia e Antônia), quando mostram partes de suas vidas. Da imagem fílmica, ressalta-se o ar elegante no sorriso da protagonista. Ora o olhar dela é extremamente sedutor, ora é terno. Há um revezamento entre risadas e uma grande declaração de amor diante da câmera.

No entanto, fecunda-se um estado perturbador da personagem. Um desenho passional emerge sonoramente de uma situação delicada que se modifica com a violência da protagonista, quando lança um tapa na câmera e pede para Antônia desligar. Tensão aguda. A circunstância crítica coloca a personagem em disjunção imediata com seu objeto de desejo, diferenciando-o propriamente do valor do objeto. Um paradoxo acena o cotejo da famosa frase de Oscar Wilde: o amor que não ousa dizer o nome.

Na película, o desvincular das amantes esboça uma perspectiva diferente para Júlia. Partes desse tipo de cena cinematográfica, perante o álbum de família (audiovisual), serão revisitadas ao longo do filme, por diversas vezes. A reiteração dessa cena específica estabelece resquícios de lembranças que demonstram bons momentos de uma saudosa companhia (parceira). A repetição dessa passagem parece ser estratégica para chamar atenção. E mais adiante, no enredo fílmico, percebe-se um forte desencanto com sentimentos de angústia e depressão. Há um espírito de desilusão amorosa e a sensação de impedimento.

Da articulação cenográfica, a locação desse prólogo fílmico estabelece a mudança do plano externo do espaço público para o plano interno de uma sala escura. Nela, Júlia queima uma fotografia que remete àquela paisagem turística do vídeo retratado anteriormente. Eis um elevado movimento transitório na narrativa, que se dinamiza pelos fatos registrados, aos poucos, em uma exploração espaço-temporal da cena (PEIXOTO, 2007).

Nessa transitoriedade, o deslocar seria inevitável, uma vez que se verifica a precária condição da protagonista, cuja ambiguidade afetiva - entre amar e/ou odiar - parece insustentável. De acordo com Marinho (2007, p.228), a “experiência de espaço informa os 
contextos, moldando paisagens que são produtos das percepções, memórias, subjetivações individuais e coletivas”. Por isso, as coisas acontecem na tensão fragmentada por espaço/ tempo, elencado por corpo, gênero e performance (CARLSON, 2009).

Durante os dois primeiros minutos do filme, Júlia aparece com os cabelos encaracolados; às vezes soltos, às vezes contidos em um gorro de lã. Afinal, percorre a paisagem gélida de Londres, apesar do amor caliente e, aparentemente, leve. Quando Júlia reaparece na cena, já no plano presente em casa, na sala escura, seus cabelos estão lisos, retos, presos e sem vivacidade. E, assim, permanecem até o fim da fita. Esse detalhe, aliado à luz do ambiente, traz o retrato do que ela está vivendo: sombra, meia luz e breu.

Júlia chora na angústia produzida pela memória de um tempo vivido. A protagonista tateia a mesa e alcança uma foto em preto e branco de Antônia. Deliberadamente, queima a foto. Talvez, como se quisesse apagar o passado, queima o papel, queima a imagem, mas ao mesmo tempo (re)alimenta a lembrança. O assombro do fantasma da ex-amada permanece inserido em si. A última chama desse ritual é abafada com sua própria mão. Castigo. O sacrifício de tentar se desvincular do amor traduzido em ódio na dor do vazio estendido ao abandono. A rejeição dói. Sem dúvida, tal história (re)dimensiona a questão da perda, expõe a intimidade da personagem e instiga determinada descrição cênica de imagem e som.

\section{Do som}

Já conheço os passos dessa estrada

Sei que não vai dar em nada

Seus segredos sei de cor Já conheço as pedras do caminho

E sei também que ali sozinho

Eu vou ficar, tanto pior

O que é que eu posso contra o encanto

Desse amor que eu nego tanto

Evito tanto

E que no entanto

Volta sempre a enfeitiçar

Com seus mesmos tristes velhos fatos

Que num álbum de retrato

Eu teimo em colecionar

Lá vou eu de novo como um tolo

Procurar o desconsolo

Que cansei de conhecer

Novos dias tristes, noites claras

Versos, cartas, minha cara 
Ainda volto a lhe escrever Pra lhe dizer que isso é pecado

Eu trago o peito tão marcado

De lembranças do passado

E você sabe a razão Vou colecionar mais um soneto Outro retrato em branco e preto A maltratar meu coração (BUARQUE; JOBIM, 1974).

Para legitimar a leitura descritiva do prólogo, neste trabalho, torna-se fundamental ambientar algumas impressões acerca da trilha musical que, de modo confortável, coaduna com a imagem - exposta no tópico anterior. Anotam-se predileções, pois a qualidade da seleção musical auxilia na ilustração audiovisual, ao introduzir a problemática da cena.

Para compor tal articulação audiovisual, a música Retrato em Branco e Preto (1974), de Chico Buarque e Tom Jobim, configura-se ao fundo na voz serena e, ao mesmo tempo, dramática da cantora Elis Regina. Ela vibra a intensidade do texto sonoro que desperta no/a observador/a o enredo da trama, em uma expressividade única. Um som inigualável. A estratégia sonora, portanto, acomoda o/a espectador/a na recepção da mensagem cinematográfica. A letra denuncia um lamento de afeto e memória, que se envereda pela situação complicada entre a separação aborrecida e a impossibilidade de continuar a viver. As amarguras inconsoláveis de um amor caído são, romanticamente, acenadas para o absurdo de alguém que não consegue mais desfrutar da vida, sem a presença do/a outro/a.

A canção dura por volta de dois minutos iniciais da narrativa fílmica, em sintonia com a imagem de Júlia; embora seja tempo suficiente para arquitetar o drama desse amor despedaçado. Nesse sentido, a compatibilidade obstinada de melodia e letra adiciona elementos contundentes ao drama vivenciado pela protagonista.

Nesse caso, a música tem o papel de prelúdio (tema inicial, abertura de uma peça), porque o canto direciona a atenção do/a observador/a para o enredo da obra e enuncia o que, provavelmente, irá acontecer - o que está por vir. Indiscutivelmente, é um áudio sagaz para a ocasião, pois a carga poética nessa canção expõe as fraturas de um amor trágico, que clama por vontade de se desligar do mundo. O álbum de Retrato em Branco e Preto, envelhecido, traz recordações emblemáticas que apontam para o caminho a ser seguido, para evitar a desilusão. Muito embora, a força dramática aciona uma potencialidade sensível do conjunto audiovisual. São idiossincrasias inerentes ao projeto cinematográfico.

Ao discutir acerca de música popular e crítica no Brasil, Vargas (2014, p.6) afirma:

Assim como os elementos constitutivos dos gêneros constroem identificações e identidades na cultura, o contrário também ocorre: qualquer manipulação 
na execução de alguns estilemas dos gêneros, seja com exagero, inversão ou mescla com outros códigos musicais, pode redundar em alteração de sentido e consequente quebra de identificação. A rigor, as ações de reconhecimento e aproximação, de um lado, e as de afastamento, de outro, são apenas dois extremos de uma relação complexa, móvel e com múltiplos resultados. Canções e gêneros na música popular nas mídias são nômades, ou seja, sofrem mais trânsitos estilísticos e de consumo do que suas definições conceituais conseguem circunscrever. Essas transformações podem ser, inclusive, motivo de criação e inovação dentro do gênero, com prejuízos ou sucessos no consumo das novidades.

Na estreita interface de projeção/identificação, a música toca o/a espectador/a de imediato. O tom acústico da mensagem musical propicia, em seu ritmo melancólico, a compreensão do enunciado audiovisual - entre codificação e/ou decodificação do código. A tessitura sonora da letra musical adoça a imagem na suavidade das palavras escolhidas, que condiz com a capacidade de síntese na trama. A aproximação de letra e melodia formaliza um lamento de amor: lento e triste.

Para Tatit (1994), a passionalização aborda a espera e a lembrança, cuja passagem sonora impacta o/a ouvinte. A duração do lamento e da dor faz o sujeito refletir sobre seus sentimentos. Essa escritura, inebriada pela trilha sonora pontual, promove um resgate da memória, cujo/a espectador/a compreende com a soma de fatores expostos ao longo da narrativa. Então, como não esquecer?!

\section{Da memória}

A memória vivenciada em determinados filmes exibe, estrategicamente, propriedades de afeto, ao resgatar particularidades de um fato vivido. Ao longo do filme Como esquecer, cenas de flashbacks funcionam como intervalos de uma construção narrativa que se reitera. Vai e volta. Repete. Recompõe. Em vários momentos, a lembrança restabelece uma relação da protagonista com o evento nostálgico do amor perdido. Tais lembranças caracterizam uma etapa importante a ser descortinada, aos poucos, no roteiro. São pontos relevantes que (re)organizam a possibilidade do viver (GARCIA, 2012).

A personagem decide alimentar-se de lembranças, como afagos soturnos de diferentes instantes reminiscentes. Tempo fragmentado: dividido, parcelado, quebrado. As transversalidades do tempo (diacrônico e/ou sincrônico) nessa narrativa cinematográfica aliam-se às cenas de flashbacks (com filmagens domésticas do casal, em passeios ou viagens), que entrecruzam e suturam emoções. O eixo de tal tessitura narrativa explora diferentes embates para suplantar a melancolia nesse amor ultrapassado. No cotejo de confrontos, o cronológico cede lugar aos desfechos que revolvem o passado, o qual se 
(re)inscreve no presente. A duração infinita das representações das coisas no mundo. Da memória, qualquer fato anterior ganha força mediante o corrente.

Desse modo, o tempo fílmico instaura-se em um processo lento da memória que oscila, por ora se apaga, mas também retoma. É um tempo suave que aguça a imaginação. Prevalece uma calmaria introspectiva e, ao mesmo tempo, revolucionária, porque há algo conturbador em sua vida afetiva. Por isso, Júlia tenta, inclusive, ressignificar o amor. Mas, não consegue se desprender das imagens do passado feliz, com a amada, que invade seu cotidiano. Na verdade, escolheu entristecer e embrutecer na dor. O que causa vertigem.

A intensidade da emoção permite muito mais o registro na memória desse sofrimento que fica. Júlia está presa ao passado, quase não consegue reagir, e faz o mesmo com o/a espectador/a, quando acrescenta seu testemunho. Agarra-se ao que já ocorreu, a reviver a angústia e o pesadelo dessa atormenta. Retoma a cena de um estado de felicidade pleno para valorizar o momento único presente em sua memória.

A unidade dos padrões de memória consiste em expressão da unidade do discurso midiático construído desde há muito, com seus próprios modos de expressão peculiares. Este discurso, mesmo que incorpore também origens internacionais, adapta-se às exigências comunicacionais nacionais e locais, atendendo a demanda dos receptores que o reconstroem (LOPES, 2002, p.12).

Para Gumbrecht (2010), a força do passado presentifica-se na memória. Essa última reconstitui os sentidos do sujeito quando pondera e seleciona o que parece ser relevante para se ter em mente. São resíduos de arquivos escondidos, confinados, da memória, que pautam agora o cotidiano. Será (re)criar e/ou preservar experiências recorrentes. Grosso modo, a vida se vale de uma pluralidade de dados e informações que, de maneira versátil, comportam o viver. Portanto, a memória torna-se um complexo processo de experiência e subjetividade, porque inscreve (aquisição, consolidação e/ou recuperação de) anotações da vida.

Notadamente, valem as prioridades, armadas por sua relevância pontual da memória: de curto, médio ou longo prazo. Memória, que documenta fatos e/ou dados, possibilita considerar aquilo que importa ao sujeito. Vestígios, índices, fragmentos do viver. Cenas que ficaram impregnadas na memória (re)velam o (des)conhecido. Conhecer é avançar. Isto é, implica potencializar a memória para mediar o fluxo de possibilidades que permeiam de produção de subjetividade, entrelaçado pela experiência. A memória, então, ativa estímulos internos e/ou externos na condição adaptativa do sujeito no mundo.

Não há como esquecer. A memória traz à tona as tentativas de Júlia para negar o grande amor no desapego daquela relação, diante do enorme desgosto. A personagem desesperada respira uma atmosfera de dificuldade e pavor. Picos de estresse alternam-se com contemplação receosa. Júlia parece não querer esquecer, pois mergulha profundamente em 
uma caverna de temor e fragilidade. O que estaria (de)marcado para ambas como destino foi desfeito. Antônia partiu e Júlia não aceita, está desmantelada. O relacionamento amoroso acabou. Parece ser irreversível, visto que não há mais possibilidade de volta. Houve uma ruptura, (dis)junção, bifurcação: algo se desmanchou.

Trazer à tona uma cena/situação da memória é vasculhar uma região de conflitos e interesses, como a consciência (EAGLETON, 2012). A memória, por certo, coloniza o passado e o presente através da emoção, amparo pela experiência vivida. No movimento de inclusão/exclusão, vale correlacionar a experiência vivida e a novidade, às vezes gritantes, incongruentes e/ou incompatíveis com a realidade. O que ressalta, quem sabe, aos olhos e à imaginação. Diante de imagens impregnadas na memória, a imaginação fica muito mais estimulada, mais fértil. São impressões de experiências conquistadas e/ou fracassadas.

E a condição inusitada de memória incrementa a expressão cênica/midiática, a se espelhar nas artimanhas criativas do cinema atual. As formas de propor a narrativa desdobram à emergência da felicidade debatida no enredo (MONZANI; MONZANI, 2008).

\section{Da diversidade}

Uma problemática de Como esquecer emerge diante da carga afetiva, que se dissolve ao propor, estrategicamente, o discurso lésbico no cinema brasileiro. O que não é nada fácil. Isso transversaliza arranjos entre o romance e a película, ao realizar uma poética lésbica (ALLEN, 1996; LORDE, 1984; WITTIG, 1992), a qual anuncia a presença máxima de Safo, a décima musa de Platão: poetisa grega da cidade Lésbia de Mitilene, grande centro cultural do século VII a.C. Para Trevisan (2000, p.35), “se o desejo humano funciona com objetivos específicos (ainda que enigmáticos), é neles que se encontram sua fragilidade e sua força. [...] O desejo homossexual partilha de uma extrema pluralidade libertária - mas também dos paradoxos da padronização cultural de cada período”.

Esse discurso incorpora algumas lembranças de um bem-estar efetivo do casal lésbico; afetado pela separação - a quebra dessa aliança de anos juntas. Propositalmente, o filme problematiza o sistema hegemônico (mainstream) a ponto de questionar os referentes cotidianos do gênero, do feminino e da imagem da mulher com feixes de efeitos de sentido. Talvez, a expectativa seria provocar no/a espectador/a um ressignificar a respeito da diversidade, em específico à condição lésbica.

Nesse tipo de postura estético-política, a proposta cinematográfica questiona-se sobre a realidade, além de ultrapassar as rupturas convencionais da ideologia da transformação sociocultural. Em um viés paradoxal, uma imagem leve e tenaz expõe afetos e intimidades entre mulheres. Elegem-se texturas femininas como prioridade. Hoje, a diversidade cultural/ sexual no cinema brasileiro contagia-se de alternativas entre amizade, fidelidade, traição e homoerotismo. De acordo com Trevisan (2000, p.299), no cinema: “o amor entre mulheres 
sempre foi tratado com (discutível) complacência de voyeur - evidenciando como tais filmes visavam basicamente a satisfazer ao público masculino mais convencional”. A relação entre pessoas do mesmo sexo indica aspectos econômicos, identitários, socioculturais e políticos que o filme tangencia. E, poeticamente, essa tratativa cinemática se prevalece do amor homoafetivo (FOSTER, 2003).

Nesse caso, a protagonista tenta se reerguer da separação, que a coloca em um profundo estágio de desespero e opressiva reclusão de amarras. Vivifica-se a saudade! Júlia se sente (re)traída, pois foi abandonada pela namorada depois de uma intensa relação. No contexto coeso, uma professora homossexual tenta superar o recente desfecho da separação amorosa. Tenta a difícil tarefa de arrumar a vida para recomeçar: traçar novos planos.

\section{Considerações finais}

O escopo dessas ideias aposta em questões crítico-conceituais que se desdobram entre afeto, imagem e memória, ao ressaltar a diversidade cultural/sexual no cinema brasileiro contemporâneo. A delicadeza da matéria a ser descortinada pelo percurso cinematográfico equaciona uma máxima: as relações humanas na ordem do viver a grandeza do amor.

Imagens eloquentes tecem o emaranhado plástico de experimentações que estimulam a emergência de uma possibilidade cinematográfica atrelada à vida. Anota-se uma condição sine qua non que procura intensificar os fatos, pela sutileza de cada ação (re)velada nas cenas. Talvez, isso possa funcionar como (inter)mediação entre filme e espectador/a. O que sempre faz emergir uma empreitada investigativa de recursos estéticos, técnicos e éticos do cinema durante a pré-produção, a produção e a pós-produção. Todavia, o cinema continua sendo capaz de encantar o/a espectador/a.

Para além de um drama, tal proposta fílmica desrespeita a ordem convencional e cria um espaço alternativo à diversidade cultural/sexual, quando atualiza questões que envolvem a mulher, o gênero, o feminino - a condição lésbica. As assumidas, as malditas, as indecisas e/ou as guerreiras - ironicamente com seus (de)feitos - conclamam, politicamente, a presença lésbica no cinema brasileiro. Este estudo, portanto, privilegia uma leitura específica sobre a diversidade no cinema.

Do ponto de vista político, questões como lesbianismo, feminino, mulher necessitam de tratamento mais exclusivo, para ser melhor pesquisado, inclusive pela investigação crítica. Do universo feminino (lésbico), o filme Como esquecer designa uma resultante tão contundente quando tenta fugir de caricaturas ou estereótipos sobre comunidades Lésbicas, Gays, Bissexuais, Transgêneros, Queers, Intersexs, Assexuados e afins (LGBTQIA+), no esforço de fortalecer ações afirmativas e visibilidade.

Na exaustão contemporânea, como esquecer um amor? Difícil! Impossível! Talvez, seria um golpe extraordinário! Seria gesto da alma... 
WILTON GARCIA

\section{Referências}

AGAMBEN, G. O que é contemporâneo? e outros ensaios. Chapecó: Argos, 2009.

ALLEN, J. Sinuosities: lesbian poetic politics. Bloomington and Indianopolis: Indiana University Press, 1996.

BAITELLO JR., N. O pensamento sentado: sobre glúteos, cadeiras e imagens. Porto Alegre: Editora Unisinos, 2012.

BUARQUE, C.; JOBIM, A. C. Retrato em branco e preto. Intérprete: Elis Regina In: Elis \&Tom. Los Angeles: Phonogram, 1974.

CAMPELLO, M. Como esquecer: anotações quase inglesas. Rio de Janeiro: 7 Letras, 2003.

CARLSON, M. Performance: uma introdução crítica. Belo Horizonte: Editora UFMG, 2009.

COMO ESQUECER. Direção de Malu De Martino, 2010, filme 35mm (1h40), cor. Disponível em: http:// comoesquecer.wordpress.com/

EAGLETON, T. Marx estava certo. Rio de Janeiro: Nova Fronteira, 2012.

FOSTER, D. W. Queer issues in contemporary Latin American cinema. Austin: University of Texas Press, 2003.

GARCIA, W. Uma delicada performance em Como esquecer: estudos contemporâneos do cinema. In: MONZANI, J. et al. (Org.). Estudos de cinema e audiovisual Socine: estadual São Paulo: UFSCAR, 2012, p.326-335.

Homoerotismo \& imagem no Brasil. São Paulo: Nojosa edições/Fapesp, 2004.

GUMBRECHT, H. U. Produção de presença. Rio de Janeiro: Contracampo, 2010.

HELLER, B.; DOURADO, H.; GATTI, J.; WAJNMAN, S. Cultura midiática e grupos sociais: possibilidades de um campo de estudos. E-Compós, v.1, p.1-16, dezembro de 2004. Disponível em: http://www.e-compos. org.br/e-compos/article/view/11. Acesso em 28 nov. 2015.

LOPES, L. C. Artefatos de memória e representações nas mídias. Ciberlegenda, n.7, p.1-13, 2002. Disponível em: http://www.ciberlegenda.uff.br/index.php/revista/article/view/330/211. Acesso em 28 nov. 2015.

LORDE, A. Sister outsider: essays \& speeches. Freedom: The cross Press, 1984.

MARINHO, C. Corpo, espaço e criação: poéticas e vivências contemporâneas do espaço. In: GARCIA, W. (Org.). Corpo \& subjetividade: estudos contemporâneos, São Paulo: Factash, 2007. p.223-236.

MONZANI, J.; MONZANI, L. R. (Orgs.). Imagem / memória. São Paulo: Pedro \& João Editores, 2008.

MULVEY, L. Prazer visual e cinema narrativo. In: XAVIER, I. (Org.), A experiência do cinema. Rio de Janeiro: Graal/Embrafilme, 1983, p.437-453.

NAGIB, L. Além da diferença: a mulher no cinema da retomada. Devires, Belo Horizonte, v. 9, n.1, p.14-29, jan./jun, 2012. Disponível em: http://www.fafich.ufmg.br/devires/index.php/Devires/article/view/208. Acesso em: 21 dez. 2015.

PEIXOTO, N. B. Ver o invisível: a ética das imagens. In: NOVAES, A. (Org.). Ética: vários autores. São Paulo: Cia das Letras, 2007. p.425-453.

PELBART, P. P. What is contemporary? Afterall. v. 38, p.4-13-13, 2015. Disponível em: http://www.afterall. org/journal/issue.39/what-is-the-contemporary. Acesso em: 22 dez. 2015.

O avesso do niilismo: cartografias do esgotamento. São Paulo: n-1 edições, 2013.

SARLO, B. Tempo passado: cultura da memória e guinada subjetiva. São Paulo: Cia. das Letras; Belo Horizonte: UFMG. 2007. 
SODRÉ, M. A ciência do comum: notas para o método comunicacional. São Paulo: Martins Fontes, 2014.

SPIVAK, G. C. Pode o subalterno falar? Belo Horizonte: EdUFMG, 2010.

STAM, R. Introdução à teoria do cinema. Campinas: Papirus, 2003.

TATIT, L. A semiótica da canção: melodia e letra. São Paulo: Escuta, 1994.

TREVISAN, J. S. Devassos no paraíso: a homossexualidade no Brasil, da colônia à atualidade. 3. ed. Rio de Janeiro: Record, 2000.

VARGAS, H. Música popular e crítica: sobre critérios de análise da canção popular nas mídias - o caso "Ai se te pego”, de Michel Teló. Eco-Pós, v.17, n.3, p.1-13, 2014. Disponível em: https://revistas.ufrj.br/index.php/ eco_pos/article/view/1275. Acesso em: 20 dez. 2015.

WITTIG, M. The straight mind: and other essays. Boston: Beacon Press, 1992.

\section{Wilton Garcia}

Artista visual, doutor em Comunicação pela USP e pós-doutor em Multimeios pela Unicamp. Professor da Fatec Itaquaquecetuba e do Mestrado em Comunicação e Cultura da Uniso. Líder do Grupo de Pesquisa Mídias Contemporâneas (MIDCON) e autor de "Feito aos poucos: anotações de blog” (2013), entre outros. E-mail: 88garcia@gmail.com.

Recebido em: 25.02.2016

Aprovado em: 30.10.2018

Este artigo é publicado em acesso aberto (Open Access) sob a licença Creative Commons Attribution Non-Commercial (CC-BY-NC), que permite uso, distribuição e reprodução em qualquer meio, sem restrições, desde que sem fins comerciais e que o trabalho original seja corretamente citado. 